\title{
Factors associated with utilization of LLINs among women of child-bearing age in Igabi, Kaduna State, Nigeria
}

Obafemi J. Babalola1,2*0, Mohammed N. Sambo ${ }^{3}$, Suleiman H. Idris ${ }^{3}$, Ike-Oluwapo O. Ajayi ${ }^{4}$, Olufemi Ajumobi ${ }^{2,5}$ and Patrick Nguku²

\begin{abstract}
Background: The long-lasting insecticidal nets (LLIN) are effective against prevention of malaria and its utilization has been proven to save lives. Despite the mass distribution of LLIN, Nigeria remains the country with the highest malaria burden in Africa. The awareness of LLIN in Nigeria is high, but the utilization is low. The aim of this work is to describe factors associated with the utilization of LLIN among women of child-bearing age (WCBA) in Igabi, Kaduna, Nigeria.

Methods: A cross-sectional survey was conducted among 630 WCBA selected using a multi-stage sampling at 63 randomly selected villages in Igabi Local Government Area of Kaduna State. Trained female data collectors administered pre-tested structured questionnaires adapted from the Malaria Indicator Survey. Information collected were demographic profile, knowledge of LLIN as a preventive strategy for malaria, and LLIN ownership and utilization. LLIN utilization was assessed by identifying household members that slept under the hanged LLIN the night before the survey. Questions on the awareness of LLIN, ability to define what it is, use of LLIN, what differentiates LLIN from other bed nets, and duration of use before replacement, were scored and categorized as good, average and poor knowledge of LLIN.
\end{abstract}

Results: A total of 629 WCBA was sampled, their mean age ( \pm SD) was 29.3 ( \pm 6.2 ) years, $22.0 \%$ were pregnant, $40.5 \%$ had no formal education, $41.1 \%$ were employed, and $47.7 \%$ lived in rural communities. Awareness and good knowledge about LLINs for the prevention of malaria was $96.0 \%$ and $24.0 \%$, respectively. The proportion of women who slept under a LLIN the night before the survey (utilization) was 70.0\% and slightly higher (74.0\%) among pregnant WCBA. Women who lived in rural communities were more likely to utilize LLINs compared to their urban counterparts (OR 3.4; 95\% Cl 2.3-4.9). Younger women (aged < 30 years) were less likely to utilize LLINs compared to the older women (OR 0.7; $95 \% \mathrm{Cl} 0.5-0.9)$.

Conclusions: The knowledge of LLIN among WCBA was poor, but LLIN utilization was moderate. Living in rural communities and older WCBA were significant characteristics associated with LLIN utilization. Strategies that will improve the utilization of LLIN among the young and urban WCBA should be the focus of the Malaria Elimination Programme (MEP).

Keywords: Malaria, Insecticide-treated bed nets, Ownership, Awareness, Knowledge, Nigeria

\footnotetext{
*Correspondence: drfemibabs@yahoo.com

1 Liberia Field Epidemiology and Laboratory Training Programme,

National Public Health Institute, Congo Town, Montserrado, Liberia

Full list of author information is available at the end of the article
} 


\section{Background}

Malaria is a global health concern with an estimated 219 million cases in 2017 and $92 \%$ of all cases from the Afro-region of the World Health Organization (WHO) [1]. Nigeria leads other ten African countries with a high burden of malaria and accounted for $25 \%$ of total malaria cases and 19\% of malaria deaths worldwide in 2017 [1]. The use of long-lasting insecticidal nets (LLINs) is one of the integrated vector control strategies adopted on the Abuja Roll Back Malaria Initiatives Programme and has been proven to be a cost-effective way of saving lives [2, 3]. LLINs effectively averted $69 \%$ of 663 million malaria cases in 2015 [4]. LLIN household ownership in Nigeria increased from $44 \%$ in 2010 to $69 \%$ in $2015[5,6]$. This was the result of routine and periodic mass LLIN distribution for rapid scale-up of LLINs in the communities. However, household LLIN ownership does not translate to utilization.

Factors affecting the utilization of LLIN among those that own at least one LLIN are numerous. Some of these factors are the perception of physical discomfort due to heat while sleeping under LLINs [7], low mosquito density in the sleeping room [7], the inability to hang available nets following mass distribution possibly due to lack of skill or no space to hang the nets [8], inadequate or no educational campaigns following LLIN distribution [8, 9], having a family size of 4 or less [10], not having heard of insecticide-treated nets in last 6 months [10], preference for specific shapes and colour of the nets [11], number of nets hung in the household for use by household members [11], and individual educational status and knowledge on the benefits of the LLIN utilization [12]. Non-utilization of LLIN may contribute to the high burden of malaria and slow progression to malaria elimination [1].

The role of awareness or knowledge to improve utilization of health commodities demonstrated in various studies has been equivocal $[9,13]$. However, improved utilization of LLIN among pregnant women was attributed to their knowledge of the benefits of LLIN utilization and the risk of having malaria in pregnancy. Risks such as anaemia, low birth weight, and abortion make pregnant women use LLIN [14]. The terms "awareness" and "knowledge" are mostly interchanged [15]. According to Trevethan, the knowledge domain is a continuum from general knowledge of awareness to a piece of detailed and specific knowledge [15]. Therefore, providing detailed behavioural change communication interventions and specific knowledge on LLIN, rather than general knowledge or awareness would further promote LLIN utilization [9, 16-18].

High awareness and good knowledge of LLIN exist in Nigeria, but low utilization below the $80 \%$ target for population coverage persists [19]. In a household with at least one LLIN, $62 \%$ of women slept under an LLIN the previous night [6]. Women of child-bearing age (WCBA) described as women in the age group 15-49 years, are more vulnerable to malaria with low LLIN utilization [17]. Studies on LLIN utilization are however more focused on pregnant women, due to their vulnerability to malaria-causing maternal anaemia, preterm delivery, and low birth weight, rather than on all women of childbearing age. Generally, women of child-bearing age are more likely to share their sleeping space with children under five; hence their net usage patterns help to protect children under 5 years from malaria. The objective of this study is to describe the characteristics of WCBA associated with LLIN ownership and utilization. The ethical approval referenced MOH/ADM/744/VOL.1/326 was obtained from the Ethical Review Committee of Ministry of Health, Kaduna State, Nigeria.

\section{Methods \\ Study area}

Igabi Local Government Area (LGA) with headquarters at Turunku, is one of the 23 LGAs in Kaduna State Nigeria. It has a population of 557,624 and is sub-divided into five urban districts, which are, Afaka, Birnin-yero, Kwarau, Rigachikun and Rigasa, and seven rural districts namely; Fanshanu, Gwaraji, Igabi, Kerawa, Sabo-Birnin, Turunku, and Zangon-aya. The LGA is located $650 \mathrm{~m}$ above sea level, between latitude $10^{\circ} 47^{\prime} 0^{\prime \prime} \mathrm{N}$ and longitude $7^{\circ} 46^{\prime} 0^{\prime \prime} \mathrm{E}$ in the tropical Sahel to Sudan Savannah with annual rainfall varying from 1000 to $1500 \mathrm{~mm}$ and highest precipitation of $72 \%$ in August. The rainy season is usually from May to October. The annual mean temperature is $34{ }^{\circ} \mathrm{C}$. This can rise to $41{ }^{\circ} \mathrm{C}$ at the peak of the dry season in April and drop to as low as $12{ }^{\circ} \mathrm{C}$ in January during severe harmattan. This climatic condition influences the breeding and survival of malaria mosquitoes, and transmissions occur throughout the year. The incidence [20] and prevalence of malaria cases among under-five children at Igabi LGA is $13.6 \%$ and 55\%, respectively. Also, 92\% of households in Kaduna State have at least one LLIN and $62 \%$ slept under LLIN the previous night [6]. This study was conducted in October 2015 at the end of the rainy season. Six months before this study, the LGA benefitted from a mass household LLIN distribution campaign conducted in Kaduna state [20].

\section{Study design}

This study employed a cross-sectional design. 


\section{Study population}

Women of child-bearing age, 15 to 49 years (WCBA) who reside in the selected households in the community for 12 months or more without cognitive deficits, or any chronic and debilitating illness that hinders participation in an effective interview were the participants.

\section{Sample size determination}

Using the formula, $\mathrm{n}=\mathrm{z}^{2} \mathrm{pq} / \mathrm{d}^{2}$ at $95 \%$ confidence interval (1.96), prevalence of WCBA in North-Western Nigeria who slept under any net a night before, $43 \%$ [21] with a confidence limit of $\pm 5 \%$, and a non-response rate of $10 \%$. To adjust the required sample size for cluster sampling design, a correction factor of 1.5 is used as a design effect, as a less heterogenous community in this district was assumed. Therefore, the calculated minimum sample size was 630 .

\section{Sampling technique}

A three-stage cluster sampling technique was used to select the participants. Ten wards were randomly selected from the Igabi LGA. This included six rural wards-Fanshanu, Gwaraji, Igabi, Sabo-Birnin, Turunku, Zangon-aya and four urban wards-Afaka, Birnin-yero, Rigachikun, and Rigasa. These were selected at first stage making 2638 villages or settlements and 161,241 households. For a cluster or village/settlement selection, the household enumeration data generated by WHO/UNICEF during micro-planning for the mass LLIN campaign in these settlements were used as the sampling frame. With a sample size of 630, to improve the validity and precision of estimates and considering a wide community representation (population variance), using a probability proportional to size, 63 villages or clusters were randomly selected with a cluster size of 10.

Using the list of the households in each village/settlement generated during microplanning for mass LLIN distribution, ten households were systematically selected from each village/settlement. After the community entry at the traditional leader's house, the first selected household was located and thereafter every Kth household was recruited into the study until all the 10 households. In a household with multiple eligible WCBA, one was selected by the ballot method and recruited into the study. Any household without eligible participants is an ineligible household.

\section{Data collection tools and technique}

Data was collected from September to October 2015, by ten trained female community health workers who speak English and Hausa languages fluently and reside within the district. They were supervised by five undergraduate medical students. The data collectors used a pretested, structured questionnaire adapted from the Malaria Indicator Survey [22, 23] and other literature [24, 25] to collect information from the respondents. Information collected from the respondents included their demographic profile, knowledge of LLIN as a malaria prevention strategy, LLIN ownership and utilization, and influencers of LLIN utilization. The utilization of LLIN was verified by asking if the LLIN was used and who among the household members had slept under a LLIN the night before the survey. The interviewers also inspected and documented the conditions of all nets in the household to determine if they were used, unused, torn, hung, new or old. The LLIN knowledge items were questions from the literature, Malaria Indicator Survey and Demographic Health Survey. The adapted questions were reviewed by two malaria subject matter experts for face and content validity. They focused on the item's accuracy, relevance and clarity. However, face validity was assessed by five malaria researchers and 15 WCBA for relevance to the WCBA. Following the review and corrections, each correct response was scored [9] "1" and incorrect " 0 ". The aggregate score for each respondent was expressed as percentage. Knowledge was categorized using percentile scores of 75th percentile or more for good knowledge, average knowledge between 50th and 74th percentile, and poor knowledge as $<50$ th percentile.

\section{Study variables}

The outcome or dependent variable for this study was LLIN utilization. LLIN ownership was defined as having at least one LLIN within the household that may be used for sleeping and utilization is to sleep inside hung LLIN a night before the survey. Independent and explanatory variables are respondents' demographic characteristics, LLIN ownership, and knowledge items.

\section{Data processing and analysis}

Data was entered and analysed using Epi-Info version 7 statistical software. Frequency and proportions for sociodemographic characteristics, knowledge of LLIN, ownership and LLIN utilization were calculated. Ownership was the proportion of WCBA living in a household with any net for sleeping; its denominator was the total number of households sampled. Utilization referred to the proportion of respondents that slept under LLIN a night before the survey. Therefore, the denominator is the number of WCBA with LLIN. The mean $( \pm$ standard deviation) or median for continuous descriptive variables, were also calculated. Bivariate analysis using odd ratio was done to determine the association between 
categorical outcome and independent variables and any associated factors with $\mathrm{p}$-value $\leq 0.2$ selected for a multivariable logistic regression model with an upward loading approach to identify factors independently influencing LLIN ownership and LLIN utilization among WCBA. For all statistical analyses, the significance level was set at a p-value of $<0.05$ and a $95 \%$ confidence interval.

\section{Results}

\section{Respondent's demographic characteristics}

The response rate was $99.8 \%$. Table 1 shows the sociodemographic characteristics of the respondents. A total of 629 WCBA interviewed, their mean age ( \pm standard deviation) was 29.3 ( \pm 6.2 ) years, about $22.0 \%$ were currently pregnant, $40.5 \%$ had no formal education, $41.1 \%$ were employed, $47.7 \%$ were living in rural communities, $57.4 \%$ were housewife and $84.3 \%$ were Hausa by tribe.

Table 1 Sociodemographic characteristics of WCBA, Igabi LGA, Kaduna Nigeria, 2015 ( $N=629)$

\begin{tabular}{|c|c|c|}
\hline Characteristics of WCBA & Frequency (n) & Percentage (\%) \\
\hline \multicolumn{3}{|l|}{ Age group (years) } \\
\hline $20-24$ & 112 & 17.8 \\
\hline $25-29$ & 204 & 32.4 \\
\hline $30-34$ & 184 & 29.3 \\
\hline $35-39$ & 82 & 13.0 \\
\hline $40-44$ & 47 & 7.5 \\
\hline \multicolumn{3}{|l|}{ Educational level } \\
\hline None & 255 & 40.5 \\
\hline Primary & 144 & 22.9 \\
\hline Secondary & 174 & 27.7 \\
\hline Tertiary & 56 & 8.9 \\
\hline \multicolumn{3}{|l|}{ Tribe } \\
\hline Hausa & 530 & 84.3 \\
\hline Fulani & 39 & 6.2 \\
\hline Yoruba & 15 & 2.4 \\
\hline Igbo & 9 & 1.4 \\
\hline Others & 36 & 5.7 \\
\hline \multicolumn{3}{|l|}{ Occupation } \\
\hline Housewife & 361 & 57.4 \\
\hline Trader & 111 & 17.7 \\
\hline Civil servant & 60 & 9.5 \\
\hline Craft/artisan & 54 & 8.6 \\
\hline Farmer & 34 & 5.4 \\
\hline Student & 9 & 1.4 \\
\hline \multicolumn{3}{|l|}{ Marital status } \\
\hline Married & 620 & 98.6 \\
\hline Divorced/separated & 9 & 1.4 \\
\hline \multicolumn{3}{|l|}{ Place of residence } \\
\hline Rural & 300 & 47.7 \\
\hline Urban & 329 & 52.3 \\
\hline
\end{tabular}

Table 2 Respondents knowledge of Long-Lasting Insecticidal Nets, Igabi LGA, Kaduna, 2015 ( $n=629)$

\begin{tabular}{|c|c|c|}
\hline LLIN knowledge items & $\begin{array}{l}\text { Frequency } \\
(n=629)\end{array}$ & Percentage (\%) \\
\hline \multicolumn{3}{|l|}{ Aware of LLIN } \\
\hline Yes & 606 & 96.3 \\
\hline No & 23 & 3.7 \\
\hline \multicolumn{3}{|l|}{ Duration of LLIN awareness (months) } \\
\hline$<13$ & 308 & 49.0 \\
\hline $13-24$ & 237 & 37.7 \\
\hline$>24$ & 61 & 9.7 \\
\hline Not aware & 23 & 3.6 \\
\hline \multicolumn{3}{|l|}{ What is LLIN } \\
\hline Free net given by government & 283 & 45.0 \\
\hline $\begin{array}{l}\text { Insecticide impregnated last- } \\
\text { ing }>3 \text { years }\end{array}$ & 186 & 29.6 \\
\hline Net for sleeping & 133 & 21.1 \\
\hline Don't know & 27 & 4.3 \\
\hline \multicolumn{3}{|l|}{ Uses of LLIN } \\
\hline Sleeping under prevent malaria & 349 & 55.5 \\
\hline For sleeping only & 170 & 27.0 \\
\hline Prevent mosquito bite & 76 & 12.1 \\
\hline To build cage and fence farm & 11 & 1.7 \\
\hline No response & 23 & 3.7 \\
\hline \multicolumn{3}{|l|}{ Differentiate LLIN from other nets } \\
\hline Factory impregnated insecticide & 232 & 36.9 \\
\hline Don't know & 371 & 59.0 \\
\hline No response & 22 & 3.5 \\
\hline Nothing & 4 & 0.6 \\
\hline \multicolumn{3}{|l|}{ LLIN replacement period (years) } \\
\hline$<1$ & 37 & 5.9 \\
\hline $1-2$ & 288 & 45.8 \\
\hline$>2$ & 279 & 44.4 \\
\hline Don't know & 25 & 3.9 \\
\hline
\end{tabular}

\section{Knowledge of women of child-bearing age on LLIN and associated factors}

LLIN awareness among the women was $96.3 \%$ and $36.9 \%$ WCBA were able to differentiates LLIN from other bed nets by its factory impregnated insecticide (Table 2). LLIN was described by $45.0 \%$ WCBA as a free net given by the government, $29.6 \%$ as nets with impregnated insecticide that last longer more than 3 years, kill and prevent mosquito bite, and $21.1 \%$ of respondents said it is used for sleeping. The replacement period for LLIN was said to be $>2$ years by $44.4 \%$ WCBA. On the use of LLIN, 67.6\% responded that LLIN can be used to prevent mosquito bite and $36.9 \%$ knew that factory impregnated insecticide differentiates LLIN from other household nets. Overall, 24.0\% (151/629) WCBA had good knowledge of LLIN (Table 3). 
Table 3 Level of knowledge classification of LLIN among WCBA, Igabi LGA, Kaduna, 2015

\begin{tabular}{lll}
\hline Knowledge classification & Frequency & Percentage (\%) \\
\hline Good & 151 & 24.0 \\
Average & 318 & 50.6 \\
Poor & 160 & 35.4 \\
Total & 629 & 100 \\
\hline
\end{tabular}

\section{LLIN ownership and utilization}

In overall, $68.6 \%(341 / 497)$ of WCBA got LLIN in the last 7 months and ownership of at least one LLIN for sleeping by WCBA was $79 \%$ (497/629). The mean ( \pm SD) household residence per LLIN was $2.6( \pm 1.7)$ not different from the household with pregnant WCBA (Tables 4 and 5). Despite having at least one LLIN for sleeping, 6\%
(30/497) did not hang the available LLIN because they have no place to hang it and $13.1 \%(65 / 497)$ hanged more than enough bed nets for the use of household members. But 2.4\% (12/497) did not hang the available LLIN because they did not know how to do it.

Generally, LLIN utilization was 69.9\% (440/629), but in a household with at least 1 LLIN for sleeping, $75 \%$ (373/497) WCBA utilized it. Among the 137 currently pregnant WCBA, $82 \%(112 / 137)$ owns at least one LLIN and $74 \%(101 / 137)$ utilized it. However, $79 \%(89 / 113)$ of pregnant WCBA with at least one LLIN slept under LLIN a night before.

The reasons for not having at least 1 LLIN by 132 WCBA were dislike to LLIN (56.8\%), not knowing where to get LLIN (40.2\%), using other malaria preventive measures $(34.8 \%)$, no money to buy (25.8\%), no voucher to collect free LLIN during mass distribution campaign

Table 4 Indicators of LLIN ownership and utilization among WCBA per wards, Igabi LGA, Kaduna, 2015 (n=629)

\begin{tabular}{|c|c|c|c|c|c|}
\hline Ward & Number $\mathrm{N}$ & $\begin{array}{l}\text { Mean household residence } \\
\text { per LLIN, Mean }( \pm S D)\end{array}$ & $\begin{array}{l}\text { Proportion that owns } \\
\text { at least } 1 \text { LLIN, } n(\%)\end{array}$ & $\begin{array}{l}\text { Proportion that slept } \\
\text { under LLIN, } n(\%)\end{array}$ & $\begin{array}{l}\text { Proportion that owns at least } 1 \\
\text { LLIN that slept under LLIN, } n(\%)\end{array}$ \\
\hline \multicolumn{6}{|c|}{ Among all women of child-bearing age } \\
\hline Afaka & 50 & $1.7(0.6)$ & $41(82)$ & $30(60)$ & $25(61)$ \\
\hline Birnin yero & 40 & $2.0(0.9)$ & $32(80)$ & $30(75)$ & $24(75)$ \\
\hline Fanshanu & 30 & $2.2(1.1)$ & $27(90)$ & $26(87)$ & $24(89)$ \\
\hline Gwaraji & 40 & $1.9(0.6)$ & $36(90)$ & $30(75)$ & $27(75)$ \\
\hline Igabi & 30 & $3.2(2.0)$ & $30(100)$ & $29(97)$ & $29(97)$ \\
\hline Rigachikun & 50 & $2.7(0.7)$ & $42(84)$ & $41(82)$ & $41(98)$ \\
\hline Rigasa & 229 & $3.1(2.1)$ & $144(63)$ & $121(53)$ & $83(58)$ \\
\hline Sabo birnin & 70 & $2.8(1.5)$ & $61(87)$ & $59(84)$ & $50(82)$ \\
\hline Turunku & 60 & $2.0(1.2)$ & $56(93)$ & $51(85)$ & $48(86)$ \\
\hline Zangon-aya & 30 & $3.7(3.2)$ & $28(93)$ & $23(77)$ & $22(79)$ \\
\hline Total & 629 & $2.6(1.7)$ & $497(79)$ & $440(70)$ & $373(75)$ \\
\hline
\end{tabular}

Table 5 Indicators of LLIN ownership and utilization among pregnant WCBA per wards, Igabi LGA, Kaduna, 2015 $(\mathrm{n}=137)$

\begin{tabular}{|c|c|c|c|c|c|}
\hline Ward & Number, $\mathbf{N}$ & $\begin{array}{l}\text { Mean household residence } \\
\text { per LLIN, Mean }( \pm S D)\end{array}$ & $\begin{array}{l}\text { Proportion that owns } \\
\text { at least } 1 \text { LLIN, n (\%) }\end{array}$ & $\begin{array}{l}\text { Proportion that slept } \\
\text { under LLIN, n (\%) }\end{array}$ & $\begin{array}{l}\text { Proportion that owns at least } 1 \\
\text { LLIN that slept under LLIN, n (\%) }\end{array}$ \\
\hline \multicolumn{6}{|c|}{ Among the pregnant women of child-bearing age } \\
\hline Afaka & 11 & $1.5(0.5)$ & $8(73)$ & $5(45)$ & $3(37)$ \\
\hline Birnin yero & 8 & $2.2(1.1)$ & $8(100)$ & $5(62)$ & $5(63)$ \\
\hline Fanshanu & 6 & $2.8(0.9)$ & $4(67)$ & $5(83)$ & $4(100)$ \\
\hline Gwaraji & 9 & $1.6(0.6)$ & $9(100)$ & $7(78)$ & $7(78)$ \\
\hline lgabi & 13 & $3.3(1.1)$ & $13(100)$ & $13(100)$ & $13(100)$ \\
\hline Rigachikun & 1 & $2.0(0.0)$ & $1(100)$ & $1(100)$ & $1(100)$ \\
\hline Rigasa & 44 & $2.6(1.5)$ & $28(64)$ & $27(61)$ & $19(68)$ \\
\hline Sabo birnin & 16 & $3.6(1.7)$ & $14(87)$ & $14(88)$ & $12(86)$ \\
\hline Turunku & 17 & $1.6(0.9)$ & $17(100)$ & $14(82)$ & $14(82)$ \\
\hline Zangon-aya & 12 & $4.5(4.1)$ & $11(92)$ & $11(92)$ & $11(100)$ \\
\hline Total & 137 & $2.6(1.8)$ & $113(82)$ & $102(74)$ & $89(79)$ \\
\hline
\end{tabular}


(17.4\%), stock out of LLIN during mass distribution campaign (8.3\%), and loss the voucher during free LLIN mass distribution campaign (6.0\%). Also, 11.5\% (57/497) WCBA with at least one LLIN for sleeping in their household did not utilized it because of heat and discomforts (66.7\%); poor perception that mosquitoes still bite while sleeping under LLIN (38.6\%) and that no or low mosquito density in the sleeping room (22.8\%); have a damaged or torn LLIN for sleeping (10.5\%), LLIN in the household is inadequate as visitors used the LLIN (8.8\%), and feeling of breathlessness or choking while sleeping under LLIN (7.0\%).

\section{Factors influencing LLIN ownership}

Table 6 shows the characteristic of WCBA associated with LLIN ownership. Women who lived in in rural communities were four times more likely to own LLINs compared to their urban counterpart (OR 3.8, CI 2.5-6.0, $\mathrm{p}<0.01$ ). Younger women (aged $<30$ years) were less likely to own LLINs compared to the older women (OR 0.6, CI 0.4-0.6, $\mathrm{p}=0.01$ ). In Table 6, other respondents characteristics like having formal education (OR 0.6, CI $0.4-0.9, \mathrm{p}=0.03)$, and living in a household with less than three sleeping rooms (OR 0.4, CI 0.2-0.8, $\mathrm{p}=0.01$ ) were less likely factors associated with LLIN ownership.

Women who are currently pregnant were more likely to own LLIN compared to other non-pregnant WCBA, but it was not significant (OR 1.3; CI 0.8-2.2, $\mathrm{p}=0.3$ ). The main predictor of LLIN ownership is rural residence as women who lived in rural communities were more likely to own LLINs when compare to the urban women (aOR 3.4; 95\% CI 2.2-5.4).

\section{Factors influencing LLIN utilization}

Generally, rural WCBA is strongly associated with LLIN utilization. Women who lived in rural communities were more likely to utilize LLINs than the urban women (OR 3.4 (95\% CI 2.3-4.9) (Table 7). Also, younger women (aged $<30$ years) were less likely to utilize LLINs compared to older women (OR 0.7; 95\% CI 0.5-0.9, $\mathrm{p}=0.03$ ). Finally, after adjusting for these parameters age, currently pregnant, formal education and number Table 6 Respondents' characteristic factors associated
with LLIN ownership, Igabi LGA, Kaduna, 2015

\begin{tabular}{|c|c|c|c|c|}
\hline \multirow{2}{*}{$\begin{array}{l}\text { Characteristics } \\
\text { of WCBA }\end{array}$} & \multicolumn{2}{|c|}{ LLIN ownership $(n=629)$} & \multirow[t]{2}{*}{ Odd ratio } & \multirow[t]{2}{*}{$95 \% \mathrm{C}$} \\
\hline & Yes $(n=497)$ & No $(n=132)$ & & \\
\hline \multicolumn{5}{|l|}{ Age } \\
\hline$<30$ years & $236(74.7)$ & $80(25.3)$ & 0.6 & \multirow[t]{2}{*}{$0.4-0.9$} \\
\hline$\geq 30$ years & $261(83.4)$ & $52(16.6)$ & Ref & \\
\hline \multicolumn{5}{|l|}{ Parity } \\
\hline$<4$ & $356(79.5)$ & $92(20.5)$ & 1.1 & \multirow[t]{2}{*}{$0.7-1.7$} \\
\hline$\geq 4$ & $141(77.9)$ & $40(22.1)$ & Ref & \\
\hline \multicolumn{5}{|c|}{ Currently pregnant } \\
\hline Yes & $113(82.5)$ & $24(17.5)$ & 1.3 & \multirow[t]{2}{*}{$0.8-2.2$} \\
\hline No & $384(78.0)$ & $108(22.0)$ & Ref & \\
\hline \multicolumn{5}{|l|}{ Rural settlements } \\
\hline Yes & $269(89.7)$ & $31(10.3)$ & 3.8 & \multirow[t]{2}{*}{$2.5-6.0$} \\
\hline No & $228(69.3)$ & $101(30.7)$ & Ref & \\
\hline \multicolumn{5}{|c|}{ Had formal education } \\
\hline Yes & $284(75.9)$ & $90(24.1)$ & 0.6 & \multirow[t]{2}{*}{$0.4-0.9$} \\
\hline No & $213(83.5)$ & $42(16.5)$ & Ref & \\
\hline \multicolumn{5}{|c|}{ Good/average knowledge of LLIN } \\
\hline Yes & $423(79.5)$ & $109(20.5)$ & 1.21 & \multirow[t]{2}{*}{$0.7-2.0$} \\
\hline No & $74(76.3)$ & $23(23.7)$ & & \\
\hline \multicolumn{5}{|c|}{ Available sleeping room(s) $<3$} \\
\hline Yes & $392(76.9)$ & $118(23.1)$ & 0.4 & \multirow[t]{2}{*}{$0.2-0.8$} \\
\hline No & $105(88.2)$ & $14(11.8)$ & Ref & \\
\hline \multicolumn{5}{|c|}{ People slept here a night before $<5$} \\
\hline Yes & $264(80.2)$ & $65(19.8)$ & 1.2 & \multirow[t]{2}{*}{$0.8-1.7$} \\
\hline No & $233(77.7)$ & $67(22.3)$ & Ref & \\
\hline
\end{tabular}

Italics values indicate significance of $p$ value $(p<0.05)$
Table 7 Respondents' characteristic factors associated with LLIN utilization, Igabi LGA, Kaduna, 2015

\begin{tabular}{|c|c|c|c|c|}
\hline \multirow{2}{*}{$\begin{array}{l}\text { Characteristics } \\
\text { of WCBA }\end{array}$} & \multicolumn{2}{|c|}{ Utilization of LLIN } & \multirow[t]{2}{*}{ Odd ratio } & \multirow[t]{2}{*}{$95 \% \mathrm{Cl}$} \\
\hline & Yes $(n=440)$ & No $(n=189)$ & & \\
\hline \multicolumn{5}{|l|}{ Age (years) } \\
\hline$<30$ & $208(65.8)$ & $108(34.2)$ & 0.7 & $0.5-0.9$ \\
\hline$\geq 30$ & $232(74.1)$ & $81(25.9)$ & Ref & \\
\hline \multicolumn{5}{|l|}{ Parity } \\
\hline$<4$ & $315(70.3)$ & $133(29.7)$ & 1.1 & $0.7-1.5$ \\
\hline$\geq 4$ & $125(69.1)$ & $56(30.9)$ & Ref & \\
\hline \multicolumn{5}{|c|}{ Currently pregnant } \\
\hline Yes & $103(75.2)$ & $34(24.8)$ & 1.4 & $0.9-2.1$ \\
\hline No & $337(68.5)$ & $155(31.5)$ & Ref & \\
\hline \multicolumn{5}{|l|}{ Rural settlements } \\
\hline Yes & $248(82.7)$ & $52(27.3)$ & 3.4 & $2.3-4.9$ \\
\hline No & $192(58.4)$ & $137(41.6)$ & Ref & \\
\hline \multicolumn{5}{|c|}{ WCBA had formal education } \\
\hline Yes & $251(67.1)$ & $123(32.9)$ & 0.7 & $0.5-1.0$ \\
\hline No & $189(74.1)$ & $66(25.9)$ & Ref & \\
\hline \multicolumn{5}{|c|}{ Good or average knowledge of LLIN } \\
\hline Yes & $377(70.9)$ & $155(29.1)$ & 1.31 & $0.8-2.1$ \\
\hline No & $63(65.0)$ & $32(35.0)$ & & \\
\hline \multicolumn{5}{|c|}{ Available sleeping room(s)<3 } \\
\hline Yes & $350(68.6)$ & $160(31.4)$ & 0.7 & $0.4-1.1$ \\
\hline No & $90(75.6)$ & $29(24.4)$ & Ref & \\
\hline \multicolumn{5}{|c|}{ People slept here a night before $<5$} \\
\hline Yes & $229(69.6)$ & $100(30.4)$ & 1 & $0.7-1.4$ \\
\hline No & $211(70.3)$ & $89(29.7)$ & Ref & \\
\hline
\end{tabular}

Italics values indicate significance of $p$ value $(p<0.05)$ 
of rooms for sleeping, women who lived in rural communities were more likely to utilize LLINs compared to their urban counterparts (aOR 3.9, CI 2.5-6.0, $\mathrm{p}<0.01$ ). Also, the number of rooms for sleeping in the households positively influences the utilization of LLINs among the respondents. Women who lived in a household with 2 or 3 rooms for sleeping were more likely to use LLIN compared to those living in 1 room (aOR 1.6, CI 1.1-2.4, $\mathrm{p}=0.01)$.

\section{Discussion}

The study aimed at describing the characteristics of WCBA associated with LLIN ownership and utilization. The women population was younger ( $<30$ years of age) with the mean age of $29.3( \pm 6.2)$ years and was not different from $28.8( \pm 4.7)$ years found in a hospital-based study done among pregnant women in Abuja Nigeria [13]. Nearly half of the respondents lived in a rural community and every two out of five had no formal education. This reflects the literacy levels of WCBA in Kaduna State as reported in the Nigeria Demographic and Health Survey 2013 [5], although that of the general population of WCBA in Nigeria is slightly higher than $38.8 \%$ [6].

The general awareness of LLIN was high and similar to previous studies in Nigeria $[19,26]$. The high general awareness of LLIN in this population may be due to previous interventions on communication and social mobilization for LLIN. However, the detailed and specific knowledge of LLIN was poor as only one out of four WCBA has good knowledge of LLIN $[15,27]$. This study shows that a greater proportion of respondents with good knowledge have detailed knowledge of LLIN and its beneficial use in the prevention of malaria. The relationship between awareness and knowledge of LLIN and its utilization is equivocal. This was demonstrated in a study among pregnant women in Nigeria, where the knowledge that the use of insecticide treated nets prevents malaria strongly predicts its ownership [14]. It may be that these pregnant women received and understood a detailed and specific knowledge about LLIN and correctly linked the occurrence of malaria fever to the bites of infected mosquitoes; hence, the positive association between knowledge and LLIN ownership and utilization $[28,29]$. However, in another study from eastern Nigeria, it was demonstrated that high awareness of LLIN does not relate to LLIN ownership and utilization [26].

Higher educational status and literacy levels have been adjudged to have an impact on the uptake of malaria preventive measures [13, 30,31]. Most of the respondents reside in the urban community and the urban WCBA has better knowledge than rural women. Most urban women can easily be exposed to diverse sources of information on malaria and LLIN through the mass media and other means of public health communications. Also, they have more access to education than rural women. Although, the urban WCBA may have higher educational status [30] and exposure to communication materials on malaria and LLINs, but rural WCBA in this study owned and utilized LLIN more than the urban women. It may be that other factors rather than awareness, knowledge and educational status are responsible to LLIN ownership and utilization.

Overall, 79\% WCBA owns at least 1 LLIN and 3 out of every 4 WCBA with LLIN ownership got it during the free mass LLIN campaign that was done 6 months earlier in the district. This could account for the high LLIN ownership among respondents as shown in a study from southwestern Nigeria where households' LLIN ownership was linked to free mass LLIN distribution campaigns rather than from other sources [8]. Although the LLIN ownership in the study is lower than the 95\% reported from a study from South Western Nigeria which was done following a free LLIN mass distribution campaign [8]. Also, it was lower than $91.6 \%$ reported for household LLIN ownership for Kaduna state in the 2015 Malaria Indicator Survey (MIS) [6]. Though LLIN ownership in this study was lower compared to the $91.6 \%$ reported in the MIS, this rate could have been an increase following free mass LLIN campaign. This further support the importance of this strategy to improve LLIN ownership and coverage $[8,32]$.

Furthermore, pregnant WCBA own more LLINs compared to non-pregnant WCBA. Due to the vulnerability of pregnant women, they are prioritized during free mass LLIN campaign and routine LLIN distribution at antenatal visits. More pregnant WCBA utilized LLIN than overall WCBA. The overall LLIN utilization was 70\%, and $75 \%$ in WCBA living in a household with at least 1 LLIN. But among pregnant WCBA, LLIN utilization was $74 \%$. This was higher than $67.8 \%$ reported for Kaduna State in 2015, MIS [6]. With this moderate increase, $80 \%$ of population coverage has not been reached and may accounted for high prevalence of malaria among this vulnerable group.

The main associated factor with LLIN ownership and utilization is rural residence. This positively influences LLIN ownership and utilization by WCBA. The finding was supported by other studies $[6,14,33]$ from Nigeria. The high rural LLIN ownership by WCBA may be attributed to high rural community penetration of LLIN during free mass LLIN distribution campaigns [14]. Although, the urban women have high educational status, good awareness, knowledge of malaria and LLIN, but low LLIN utilization. This may be due to the availability, accessibility and the affordability of other malaria preventive measures in urban settings. This study also showed that, 
younger WCBA (age $<30$ years) were less likely to own and utilize LLIN when compared to older women. This has been identified by another local study [34]. This may affect the drive for malaria prevention and elimination in Nigeria as this group constitutes a large part of the population, are caregivers of under-five children, and in early child-bearing age. Therefore, there is a need for further studies on why younger women averse to LLIN utilization.

LLIN ownership does not translate to utilization [14]. Therefore, barriers to LLIN ownership and utilization as reported in the literature exist among WCBA in Igabi, Kaduna Nigeria. These barriers could be responsible for the WCBA LLIN utilization gap as reported in this study. Some of these barriers include the unwillingness to own and use LLIN, not knowing where to get LLIN, using other malaria preventive measures, not having money to buy LLIN, not having a voucher to collect free LLIN during mass distribution campaign, and stock-out of LLIN during mass distribution campaigns. Other sources of LLIN utilization gap among WCBA living in a household with at least 1 LLIN but did not utilized it because of the following reasons: heat and discomfort, feeling of breathlessness or choking while sleeping under LLIN, perception that mosquitoes still bite while sleeping under LLIN, and that most sleeping rooms have low mosquito density. To avert these limitations, a detailed but more specific knowledge on the benefit of LLIN utilization among WCBA and their underfive children should be a focus of behavioural change communication to drive the closure of LLIN utilization gap.

\section{Limitations}

The study was done at the peak of a malaria survey and about the same time when data collection for the 2015 Malaria Indicator Survey was ongoing. Nigeria is presently amongst the leading countries with a high burden of malaria and is making slow progress in efforts to reduce the malaria burden globally. The information on LLIN utilization was based on self-reported information from the participants. Data collectors observed the available LLIN in the household to know if they were hung, not hung, and if kept in its original packaging. The data collectors asked for who slept under a hung LLIN a night before the survey among the household members. Therefore, information bias like recall and social desirability are possible limitations. Efforts were made to reduce some of these limitations by piloting the questionnaire, training female data collectors to ensure standardized data collection processes, and participants were encouraged to be truthful with their responses and were assured of their confidentiality. However, it was not possible to verify actual LLIN utilization the previous night as well as confirm other self-reported data.

\section{Conclusion}

The general awareness of LLIN among WCBA is good. The detailed and specific knowledge on LLIN is poor as one out of every four WCBA has good knowledge of LLIN. Although, the ownership and utilization of LLIN were moderate in all WCBA but higher among pregnant WCBA. Rural residents and older WCBA (30 years or more) were factors associated with LLIN ownership and utilization. Though the current awareness of LLIN is high, efforts should be made to redirect behavioural change communication from creating awareness to the dissemination of detailed and specific LLIN messages tailored toward building the WCBA's knowledge on the benefit inherent in LLIN utilization [35]. The effect of malaria is more pronounced among pregnant women and WCBA was likely to share sleeping space with their under-five children. Hence, the net use patterns of WCBA extend to the protection of their underfive children and prevent malaria-causing morbidity and mortality during pregnancy. Therefore, strategies that will improve WCBA's utilization of LLIN especially among the young and urban WCBA should be the focus of the Malaria Elimination Programme (MEP).

\section{Abbreviations \\ LLIN: long-lasting insecticidal nets; LGA: Local Government Area; WCBA: women of child-bearing age; MIS: Malaria Indicator Survey; WHO: World Health Organization; UNICEF: United Nations Children's Fund. \\ Acknowledgements \\ The authors thank the Nigeria Field Epidemiology and Laboratory Training Programme (NFELTP) for the financial support for the conduct of this study. We also thank all the participants for their cooperation. We used Mendeley reference manager and Epi info software in this manuscript.}

\section{Authors' contributions}

OJB conceived the study, its design, data collection, analysis and interpretation and involved in drafting the manuscript. MNS, SHI, IOA, OA, and PN made substantial contributions to the conception, design, analysis, and interpretation of data, and revised the manuscript critically for important intellectual content. OJB, IOA, and OA participated in the data analysis interpretation. All authors read and approved the final manuscript.

\section{Funding}

This study was supported by Cooperative Agreement Number U2R6H000046 funded by the United States Centres for Disease Control and Prevention through African Field Epidemiology Network to NFELTP. Its contents are solely the responsibility of the authors and do not necessarily represent the official views of the United States Centres for Disease Control and Prevention or the Department of Health and Human Services.

\section{Availability of data and materials}

The datasets used and/or analysed during the current study are available from the corresponding author on reasonable request.

\section{Ethics approval and consent to participate}

Ethical approval referenced MOH/ADM/744/NOL.1/326 was obtained from the Ethical Review Committee of Ministry of Health, Kaduna State, Nigeria. The LGA's Director of the Primary Health Care granted verbal permission and directed the ward focal persons in charge of the selected settlements to support. Participants were informed of the nature of the survey, benefit and risks, and their right to participate and decline at any time during the interview. 
Written informed consent was obtained from each respondent before the interview but verbally seek the permission from the household head. Participants were assured of their confidentiality but identified using code numbers.

\section{Consent for publication}

Not applicable.

\section{Competing interests}

The authors declare that they have no competing interests.

\section{Author details}

${ }^{1}$ Liberia Field Epidemiology and Laboratory Training Programme, National Public Health Institute, Congo Town, Montserrado, Liberia. ${ }^{2}$ Nigeria Field Epidemiology and Laboratory Training Programme (NFELTP), Asokoro District, Abuja, Nigeria. ${ }^{3}$ Department of Community Medicine, Ahmadu Bello University, Zaria, Kaduna, Nigeria. ${ }^{4}$ Department of Epidemiology and Medical Statistics, University of Ibadan, Ibadan, Oyo, Nigeria. ${ }^{5}$ National Malaria Programme, Federal Ministry of Health, Abuja, Nigeria.

Received: 6 July 2019 Accepted: 30 November 2019 Published online: 10 December 2019

\section{References}

1. WHO. World Malaria Report 2018. Geneva, World Health Organization, 2018. https://www.who.int/malaria. Accessed 30 Jun 2019.

2. Lengeler $C$. Insecticide-treated bed nets and curtains for preventing malaria. Cochrane Database Syst Rev. 2004;2:CD000363.

3. Polec AL, Petkovic J, Welch V, Ueffing E, Tanjong Ghogomu E, Pardo JP, et al. Strategies to increase the ownership and use of insecticide- treated bednets to prevent malaria. Cochrane Database Syst Rev. 2015;3:CD009186.

4. WHO. World malaria report 2015. Geneva: World Health Organization; 2015.

5. ICF International, National Population Commission. Nigeria demographic and health survey 2013. Abuja, Nigeria, and Rockville, Maryland, USA.

6. National Malaria Elimination Programme (NMEP), National Population Commission (NPopC), National Bureau of Statistics (NBS), ICF International. Nigeria Malaria Indicator Survey 2015: key indicators. Abuja: Nigeria, and Rockville, Maryland, USA; 2016.

7. Pulford J, Hetzel MW, Bryant M, Siba PM, Mueller I. Reported reasons for not using a mosquito net when one is available: a review of the published literature. Malar J. 2011;10:83.

8. Aderibigbe SA, Olatona FA, Sogunro O, Alawode G, Babatunde OA, Olarinoye $\mathrm{AO}$, et al. Ownership and utilisation of long lasting insecticide treated nets following free distribution campaign in South West Nigeria. Pan Afr Med J. 2014;8688:1-6.

9. Fuge TG, Ayanto SY, Gurmamo FL. Assessment of knowledge, attitude and practice about malaria and ITNs utilisation among pregnant women in Shashogo District, Southern Ethiopia. Malar J. 2015;14:235.

10. Biadgilign S, Reda A, Kedir H. Determinants of ownership and utilisation of insecticide-treated bed nets for malaria control in Eastern Ethiopia. J Trop Med. 2012;2012:235015.

11. Tassew A, Hopkins R, Deressa W. Factors influencing the ownership and utilisation of long-lasting insecticidal nets for malaria prevention in Ethiopia. Malar J. 2017;16:262.

12. Adegun JA, Adegboyega JA, Awosusi AO. Knowledge and the preventive strategies of malaria among migrant farmers in Ado-Ekiti local government area of Ekiti State, Nigeria. Am J Sci Ind Res. 2011;2:883-9.

13. Akaba GO, Otubu JAM, Agida ET, Onafowokan O. Knowledge and utilisation of malaria preventive measures among pregnant women at a tertiary hospital in Nigeria's federal capital territory. Niger J Clin Pract. 2013;16:201-6.

14. Ankomah A, Adebayo SB, Arogundade ED, Anyanti J, Nwokolo E, Ladipo $\mathrm{O}$, et al. Determinants of insecticide-treated net ownership and utilisation among pregnant women in Nigeria. BMC Public Health. 2012;12:105.

15. Trevethan R. Deconstructing and assessing knowledge and awareness in public health research. Front Public Health. 2017;5:194.

16. Ajero CMU, Ukaga CN, Uzochukwu UC, Chigbo UN. Studies on the prevalence, knowledge, and practices toward malaria in Owerri West local government area of Imo State, Nigeria. West African J Ind Acad Res. 2015;14:91-9.
17. Afolabi BM, Fatunmbi BS, Otsemobor O, Sofola TO. Women in child-bearing age who are not currently pregnant are missed opportunities for malaria control in pregnancy: Evidence from 16 Local Government Areas of Nigeria. J Public Health Epidemiol. 2014;6:60-9.

18. Nwosu UM, Eke RA, Chigbu LN, Emerole CO. Utilisation of insecticide treated nets: effects of health promotion intervention in Abia State, Nigeria. ABSU J Environ Sci Technol. 2013;1:105-12.

19. Israel OK, Fawole OI, Adebowale AS, Ajayi IO, Yusuf OB, Oladimeji A, et al. Caregivers' knowledge and utilisation of long-lasting insecticidal nets among under-five children in Osun State, Southwest, Nigeria. Malar J. 2018;17:231.

20. Bajoga UA, Balarabe HS, Olufemi AA, Dalhat MM, Sule IB, Ibrahim MS, et al. Trend of malaria cases in Kaduna State using routine surveillance data, 2011-2015. Pan Afr Med J. 2019;32(Supp 1):8.

21. National Population Commission (NPC), National Malaria Control Programme (NMCP) and ICF International. Nigeria Malaria Indicator Survey 2010. Abuja, Nigeria, and Rockville, Maryland, USA: National Population Commission (NPC), National Malaria Control Programme (NMCP) and ICF International; 2012.

22. Measure DHS. Malaria Indicator Survey interviewer's manual. Fairfax: ICF International; 2013.

23. Measure DHS. Malaria Indicator Survey model household questionnaire. Fairfax: ICF International; 2012. p. 1-19.

24. Aderaw Z, Gedefaw M. Knowledge, attitude and practice of the community towards malaria prevention and control options in anti-malaria association intervention zones of Amahara National Regional State, Ethiopia. J Trop Dis. 2013;1:1-7.

25. Ruberto I, Camara S, Banek K, Loua MK. Knowledge, attitudes and practices of malaria control among communities from the health district of Forécariah in the Republic of Guinea, West Africa. J Vector Borne Dis. 2014;51:119-27.

26. Ozims SJ, Eberendu IF. Awareness, ownership, and utilization of long-lasting insecticide-treated net (LLIN) among pregnant women attending antenatal clinic in Imo State University Teaching Hospital, Orlu, Imo. Int J Res Med Health Sci. 2014;4:14-21.

27. McCallum JM, Arekere DM, Green BL, Katz RV, Rivers BM. Awareness and knowledge of the U.S. Public Health Service syphilis study at Tuskegee: implications for biomedical research. J Health Care Poor Underserved. 2006;17:716-33.

28. Birhanu Z, Yihdego YY, Yewhalaw D. Caretakers' understanding of malaria, use of insecticide-treated net and care seeking-behavior for febrile illness of their children in Ethiopia. BMC Infect Dis. 2017;17:629.

29. Aina BA, Ayeni FA. Knowledge and use of insecticide treated nets as a malaria preventive tool among pregnant women in a local government area of Lagos state, Nigeria. J Appl Pharm Sci. 2011;1:162-6.

30. Idowu A, Popoola GO, Akintunde B, Olowookere SA, Deji SA. Ownership and use of insecticide treated nets in selected rural communities of Oyo State, Nigeria: implication for policy action. Am J Public Health Res. 2016;4:222-9.

31. Belay M, Deressa W. Use of insecticide treated nets by pregnant women and associated factors in a pre-dominantly rural population in northern Ethiopia. Trop Med Int Health. 2008;13:1303-13.

32. Finlay AM, Butts J, Ranaivoharimina H, Cotte AH, Ramarosandratana B, Rabarijaona $\mathrm{H}$, et al. Free mass distribution of long lasting insecticidal nets lead to high levels of LLIN access and use in Madagascar, 2010: a crosssectional observational study. PLoS ONE. 2017;12:e0183936.

33. Otsemobor O, Ajayi OO, Afolabi BM, Ajayi JA, Longtong G, Fatunmbi BS, et al. Determinants of long-lasting insecticidal nets distribution, ownership and use in the Federal Capital Territory, Nigeria_-implications for malaria programmes. J Public Health Epidemiol. 2013;5:445-58.

34. Afolabi BM, Sofola OT, Fatunmbi BS, Komakech W, Okoh F, Saliu O, et al. Household possession, use and non-use of treated or untreated mosquito nets in two ecologically diverse regions of Nigeria-Niger Delta and Sahel Savannah. Malar J. 2009;8:30

35. Ezire O, Adebayo SB, Idogho O, Bamgboye EA, Nwokolo E. Determinants of use of insecticide-treated nets among pregnant women in Nigeria. Int J Womens Health. 2015;7:655-61.

\section{Publisher's Note}

Springer Nature remains neutral with regard to jurisdictional claims in published maps and institutional affiliations. 